\title{
Experimental neoichnology of crawling stalked crinoids
}

\author{
Krzysztof R. Brom ${ }^{1,2} \cdot$ Kazumasa Oguri $^{3} \cdot$ Tatsuo Oji $^{4} \cdot$ Mariusz A. Salamon ${ }^{1,2} \cdot$ Przemysław Gorzelak $^{5}$ (]
}

Received: 13 June 2018/Accepted: 5 July 2018/Published online: 16 July 2018

(C) The Author(s) 2018

\begin{abstract}
Stalked crinoids have long been considered sessile. In the 1980s, however, observations both in the field and of laboratory experiments proved that some of them (isocrinids) can actively relocate by crawling with their arms on the substrate, and dragging the stalk behind them. Although it has been argued that this activity may leave traces on the sediment surface, no photographs or images of the traces produced by crawling crinoids have been available. Herein, we present results of neoichnological experiments using the shallowest species of living stalked crinoid, Metacrinus rotundus, dredged from Suruga Bay (near the town of Numazu, Shizuoka Prefecture, $140 \mathrm{~m}$ depth). Our results demonstrate that isocrinids produce characteristic locomotion traces, which have some preservation potential. They are composed of rather deep and wide, sometimes weakly sinuous, central drag marks left by the stalk and cirri, and short, shallow scratch marks made by the arms. Based on the functional morphology and taphonomy, it has been argued that the ability to autotomize the stalk and relocate had already evolved in the oldest stem-group isocrinids (holocrinids), likely in response to increased benthic predation pressure during the so-called Mesozoic marine revolution. Our data show that this hypothesis may be corroborated in the future by ichnological findings, which may provide more direct proof of active locomotion in Triassic holocrinids.
\end{abstract}

Keywords Sea lilies · Traces $\cdot$ Locomotion $\cdot$ Experiments $\cdot$ Triassic

We dedicate this paper to the memory of our mentor and friend Dr. Hans Hess who recently passed away. Our joint meetings and correspondence fired up our interests in crinoids (which Hans used to call: "masterpieces of nature and the most beautiful of fossils"... We fully agree with him).

Editorial handling: C. Meyer.

Electronic supplementary material The online version of this article (https://doi.org/10.1007/s13358-018-0158-9) contains supplementary material, which is available to authorized users.

Przemysław Gorzelak

pgorzelak@twarda.pan.pl

1 Department of Paleontology and Stratigraphy, Faculty of Earth Sciences, University of Silesia in Katowice, Będzińska 60, 41-200 Sosnowiec, Poland

2 WNoZ UŚ-Centre for Polar Studies KNOW (Leading National Research Centre), Będzińska 60, 41-200 Sosnowiec, Poland

\section{Introduction}

One of the most fascinating and surprising traits of some Recent stalked crinoids, the isocrinids, is their locomotion ability. Although most isocrinids anchor only via hook-like cirri rather than a cemented holdfast or roots, no evidence existed that they could relocate. It was therefore assumed that they were sessile (e.g., Lawrence 1987). Although isocrinids include the most shallow dwelling of any extant stalked crinoids (in as little as $100 \mathrm{~m}$ depth off Japan, e.g., Oji 1986), in situ observations had to await the development of submersible technology (e.g., Macurda and Meyer

3 Department of Marine Biodiversity Research, Japan Agency for Marine-Earth Science and Technology (JAMSTEC), 2-15 Natsushima-cho, Yokosuka 237-0061, Japan

4 University Museum, Nagoya University, Furo-cho, Nagoya 464-8601, Japan

5 Institute of Paleobiology, Polish Academy of Sciences, Twarda 51/55, 00-818 Warsaw, Poland 
1974), and locomotion was not observed for another decade (Messing 1985; Messing et al. 1988; Baumiller and Messing 2007; Baumiller et al. 2008). Results obtained from these deep-sea explorations, as well as from laboratory flow-tank experiments (Baumiller et al. 1991; Birenheide and Motokawa 1994), revealed that isocrinids may actively (at a speed of up to about $\sim 30 \mathrm{~mm} / \mathrm{s}$ ) relocate by crawling with their arms and dragging the stalk behind them. Two basic types of isocrinid locomotion have been distinguished: (1) the so-called finger-tip pull, where the crawling involves a repeating sequence of movements by the proximal portions of the leading arms only, bending sharply away from the substrate; and (2) the so-called elbow-crawl, where traction with the substrate is provided by the pinnule-covered oral side of the middle third to distal half of the arms that remain strongly flexed aborally (Baumiller and Messing 2007). In both modes of locomotion, the stalk, which remains nearly straight with only the proximal portion being bent away from the bottom, is pulled passively by the crawling arms. It has been argued that this activity generates traces on the substrate. Unfortunately, due to low angles at which the video footages were shot, no detailed photos of such locomotion traces were available (Baumiller and Messing 2007). Notably, it has been only mentioned that crawling isocrinids produce two types of traces: (1) a drag mark left by the stalk, and (2) short radiating scratch marks around the central drag (Messing et al. 1988).

The aim of this study is thus to document for the first time the morphology of the traces produced by Recent isocrinids. This has been achieved by neoichnological experiments, which were carried out on the shallowest living stalked crinoid Metacrinus rotundus under controlled laboratory conditions. The detailed description of the traces made by this stalked crinoid may potentially be used for detecting isocrinid and holocrinid moving traces on bedding surfaces in the geologic record, giving evidence of crinoid motility in the past.

\section{Materials and methods}

Living specimens of the shallowest isocrinid, Metacrinus rotundus (Fig. 1), were dredged from northeastern Suruga Bay (near the town of Numazu, Shizuoka Prefecture) in June and August of $2017\left(\sim 35^{\circ} 3^{\prime} \mathrm{N}, \sim 138^{\circ} 48^{\prime} \mathrm{E}\right.$,
Fig. 1 Metacrinus rotundus during locomotion

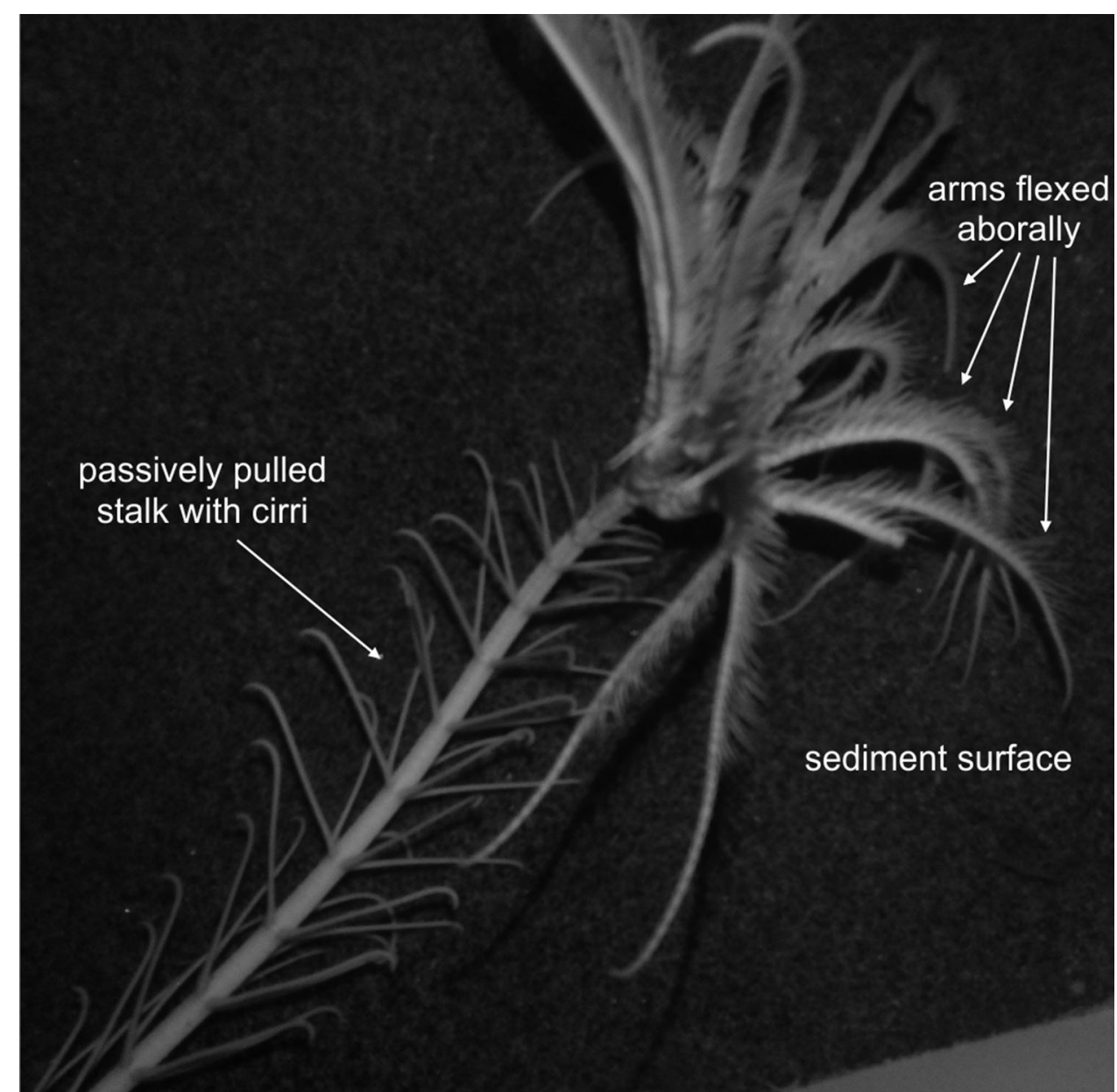



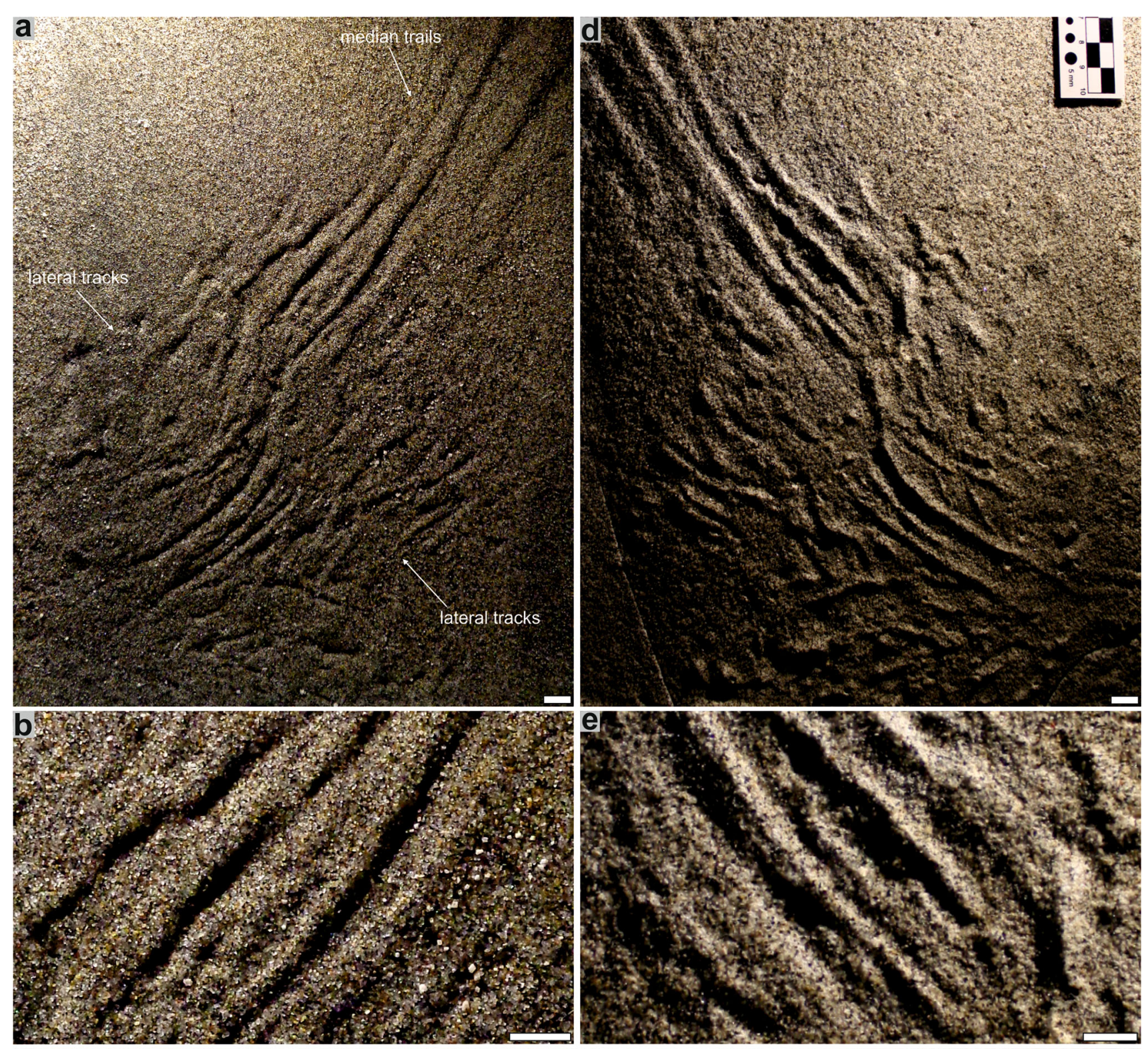

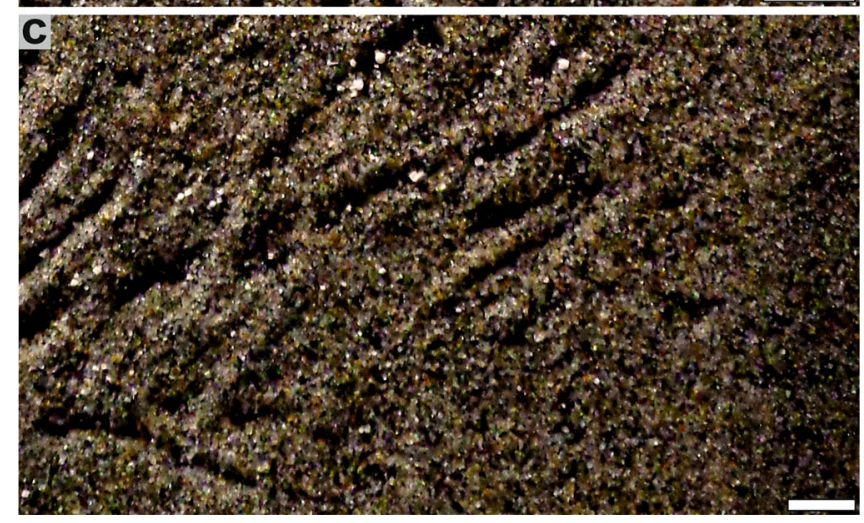

Fig. 2 Surface features produced by Metacrinus rotundus. a General view of median trails and lateral tracks left by cirriferous stalk and arms, respectively. b Close up of median trails. c Close up of lateral

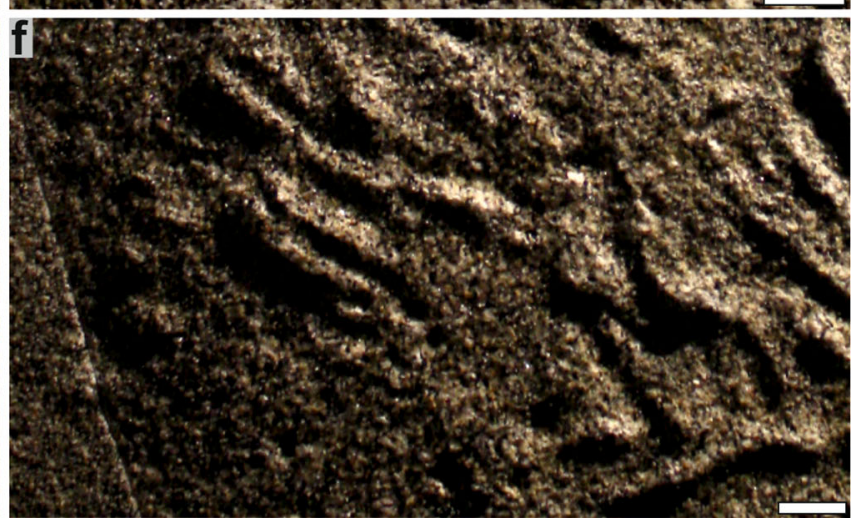

tracks. d-f. Gypsum casts (hypichnia) of the above illustrated traces (a-c; correspondingly). Scale bars $1 \mathrm{~cm}$ 
$\sim 140 \mathrm{~m}$ depth). Crinoids were collected from the sea bottom using a 90-cm-wide naturalist dredge with a net. Collected individuals $(\sim 20)$ were transferred to an experimental seawater tank in Nagoya University Museum within several hours after capture. The aquarium was maintained at a constant seawater temperature of $\sim 16^{\circ} \mathrm{C}$, in darkness and under circulation provided by a water pump. The seawater used in the experimental tank was obtained from the sea surface of the dredging site. In general, sampling and handling methodology followed Kitazawa and Oji (2010, 2014).

After 2 weeks of acclimatizing the crinoids, the experimental tank was divided into two zones ("breeding" and experimental) separated from each other by a plastic net. Within the experimental zone, we placed a $\sim 40 \times 30 \mathrm{~cm}$ box floored with fine-grained sand, which was smoothed before crinoid was introduced. The behavior of crawling crinoids was observed using a self-made underwater camera that was constructed on the basis of small single-board computer-Raspberry Pi 3 device with connected V2 Camera Module. These parts were placed into a commercially available, small transparent container with a power bank. The container box was secured with insulating tape to prevent any leaks. Raspberry Pi 3 board was combined with the source of red light that is generally less stressful for crinoids. Also, to avoid exposing crinoids to permanent light, the Raspberry Pi device was programmed to switch on the light source for only about $3 \mathrm{~s}$ while taking a picture. The camera was set to take one photograph per minute. All photographs were captured overnight for about 10-11 h (until the battery became dead). The following day, the images were downloaded and subsequently combined in time-lapse video files. At the same time, the traces on the sediment were photographed, and gypsum casts were made. These neoichnological experiments were repeated 12 times using different individuals.

\section{Results}

\section{Behavior}

Each individual displayed similar crawling behavior leaving distinct traces on the sediment surface. A crinoid usually began moving with the aid of its arms using the socalled elbow-crawl within a few hours after being introduced into the experimental zone (i.e., during the night) at a maximum speed of $\sim 1 \mathrm{~mm} / \mathrm{s}$ (Fig. 1; Supplementary Movies 1, 2). In this mode of locomotion, a repeated sequence of arm movements generated power strokes against the bottom and recovery strokes adjacent to the bottom, passively pulling the stalk along the substrate, but without active involvement of cirri. The direction of
Fig. 3 Surface features produced by Metacrinus rotundus. a General view of median trails and lateral tracks left by distalmost cirri and arms, respectively. b Close up of median trails. c Close up of lateral tracks. d-f Gypsum casts (hypichnia) of the above illustrated traces (a-c; correspondingly). Scale bars $1 \mathrm{~cm}$

locomotion commonly consisted of one straight path towards the edge of the sand box, although the turning of a crinoid leading to a change in direction, was also observed. No backwards movements were observed. In the morning, individuals were commonly found outside the box with spread crowns and were attached to the plastic net by their cirri.

\section{Traces}

Crinoids used in this study produced two different trail architectures. The most common, produced during locomotion on a more or less straight path, were horizontal traces composed of median trails left by the stalk and cirri dragged on the bottom (Fig. 2a, b, d, e), and lateral short tracks made by the crawling arms (Fig. 2a, c, d, f). Observed median trails were long, smooth and composed of up to 3 semicircular and parallel furrows, $\sim 3-7 \mathrm{~mm}$ wide. However, the width and depth of each furrows sometimes varied along the course of the trace. Likewise, transitions between trilobate to bilobate or unilobate trails were observed. The lateral depressions or grooves were commonly inclined at a low angle $\left(5^{\circ}-25^{\circ}\right)$ with respect to the median trails and started from the edge of the median trails or a few centimeters away. They were straight, sometimes oval or slightly curved, short (up to about few $\mathrm{cm}$ long $)$, rather shallow $(\sim 0.2-2 \mathrm{~mm})$ and narrow ( 1-5 mm) (Fig. 2c, f).

A rather different trail architecture was produced by individuals which were turning during locomotion (Fig. 3). In this case, the median trail was often sinuous and composed of two smooth, semicircular parallel or intersecting furrows, $\sim 4 \mathrm{~mm}$ wide, only left by the two distalmost cirri elevating the distal part of the stalk (Fig. 3a, b, d, e). In this situation, the lateral depressions (Fig. 3c, f) made by the arms were usually inclined at a considerable angle $\left(90^{\circ}\right)$ with respect to the median trail and started more than a few centimeters away. These tracks were commonly distributed asymmetrically, that is, they were present on only one side.

\section{Discussion}

The end-Permian extinction profoundly influenced the evolutionary history of crinoids, not only through a drastic decline in their diversity (Simms 1999; Twitchett and Oji 

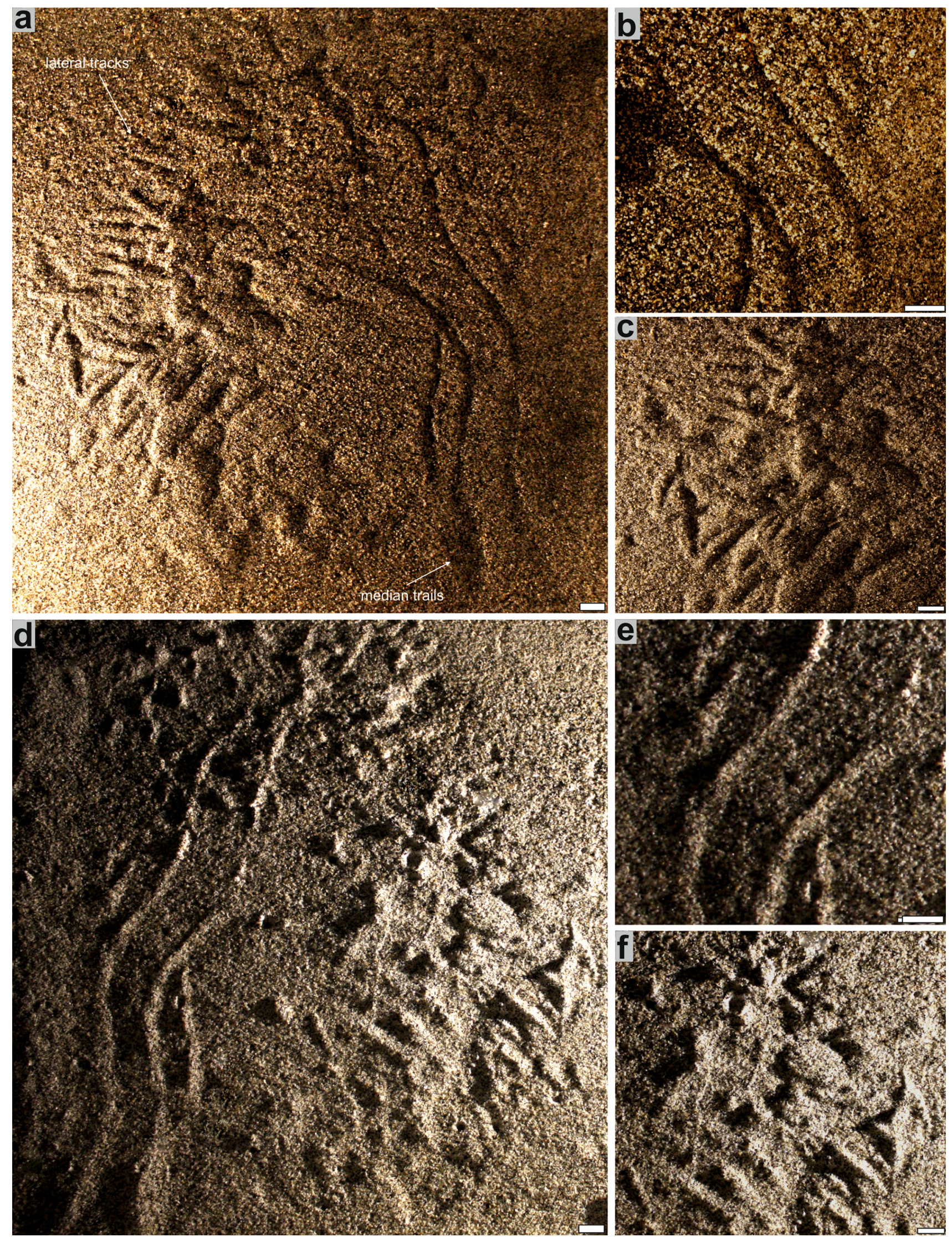
2005), but also through major functional changes (Baumiller et al. 2008, 2010). More specifically, Paleozoic crinoids, dominated by sessile forms, were replaced by predominantly motile taxa displaying many morphological and behavioral novelties (e.g., Gorzelak et al. 2012, 2016). Among these traits, autotomy planes and crawling abilities, which probably originated in the Triassic holocrinids and isocrinids (but see also Donovan 2012), are two of the best known textbook examples of dramatic functional changes in the evolutionary history of crinoids (e.g., Hagdorn 2011). Baumiller et al. (2010) argued that this novelty evolved as an effective escape strategy from echinoid predators during the so-called Mesozoic marine revolution. The ability to shed the stalk, which allowed active relocation, in the oldest post-Paleozoic stem-group isocrinids has been supported by taphonomic data (preferential disarticulation at the distal facets of nodals; see Baumiller and Hagdorn 1995), functional morphology (occurrence of highly flexible muscular arms, lack of holdfast; see, e.g., Hagdorn 2011) and micromorphology (occurrence of synostosial stereom in the distal facets of nodals, Gorzelak 2018). Our neoichnological experiment proved that isocrinids produce distinct traces on the sediment surface, which may have potential to be preserved as trace fossils. Interestingly, traces interpreted as a crawling trail of a crinoid have been recently discovered in the Middle Jurassic of Portugal (Neto de Carvalho et al. 2016). Similar trace fossils are likely to be found as early as in the Triassic. Indeed, Holocrinus-bearing beds commonly yield a wide range of trace fossils (e.g., Senkowiczowa 1982; Salamon 2003; Chrząstek 2013; MAS, personal observations), including trails, which are, however, commonly interpreted as arthropod traces. However, our neoichnological data suggest that holocrinids could be a tracemaker candidate of some of the ichnofossils observed in the Muschelkalk. We hope that our data provide a stimulus for a line of in-depth investigation of trace fossils from this age. Documenting such ichnological evidence may be particularly important, because it may provide more direct proof of active locomotion in the stem-group isocrinids.

Acknowledgements The authors are greatly indebted to Steve Donovan (Naturalis Biodiversity Center) and anonymous reviewer for their reviews. This research was supported by NCN Grants nos. 2015/19/B/ST10/01470 (MAS) and 2015/17/N/ST10/03069 (KB). Sampling of specimens of Metacrinus rotundus was conducted with the support from Scientific Aid by Japan Society of the Promotion of Science to T. O. The underwater camera was constructed thanks to the support from Japan Society of the Promotion of Science (Kakenhi, Grant number 15K12197).

Open Access This article is distributed under the terms of the Creative Commons Attribution 4.0 International License (http://creative commons.org/licenses/by/4.0/), which permits unrestricted use, distribution, and reproduction in any medium, provided you give appropriate credit to the original author(s) and the source, provide a link to the Creative Commons license, and indicate if changes were made.

\section{References}

Baumiller, T. K., \& Hagdorn, H. (1995). Taphonomy as a guide to functional morphology of Holocrinus, the first post-Paleozoic crinoid. Lethaia, 28, 221-228.

Baumiller, T. K., LaBarbera, M., \& Plotnick, R. E. (1991). Ecology and functional morphology of the isocrinid Cenocrinus asterius (Linnaeus) (Echinodermata: Crinoidea): In situ and laboratory experiments and observations. Bulletin of Marine Science, 48, 731-748.

Baumiller, T. K., \& Messing, C. G. (2007). Stalked crinoid locomotion and its ecological and evolutionary implications. Palaeontologia Electronica, 10, 1-10.

Baumiller, T. K., Mooi, R., \& Messing, C. G. (2008). Urchins in a meadow: Paleobiological and evolutionary implications of cidaroid predation on crinoids. Paleobiology, 34, 22-34.

Baumiller, T. K., Salamon, M. A., Gorzelak, P., Mooi, R., Messing, C. G., \& Gahn, F. J. (2010). Post-Paleozoic crinoid radiation in response to benthic predation preceded the Mesozoic marine revolution. Proceedings of the National academy of Sciences of the United States of America, 107, 5893-5896.

Birenheide, R., \& Motokawa, T. (1994). Morphological basis and mechanics of arm movement in the stalked crinoid Metacrinus rotundus (Echinodermata, Crinoidea). Marine Biology, 121, 273-283.

Chrzastek, A. (2013). Trace fossils from the Lower Muschelkalk of Raciborowice Górne (North Sudetic Synclinorium, SW Poland) and their palaeoenvironmental interpretation. Acta Geologica Polonica, 63, 315-353.

Donovan, S. K. (2012). Was autotomy a pervasive adaptation of the crinoid stalk during the Paleozoic? Geology, 40, 867-870.

Gorzelak, P. (2018). Microstructural evidence for stalk autotomy in Holocrinus - the oldest stem-group isocrinid. Palaeogeography, Palaeoclimatology, Palaeoecology, 506, 202-207.

Gorzelak, P., Salamon, M. A., \& Baumiller, T. K. (2012). Predatorinduced macroevolutionary trends in Mesozoic crinoids. Proceedings of the National academy of Sciences of the United States of America, 109, 7004-7007.

Gorzelak, P., Salamon, M. A., Trzęsiok, D., Lach, R., \& Baumiller, T. K. (2016). Diversity dynamics of post-Palaeozoic crinoids-in quest of the factors affecting crinoid macroevolution. Lethaia, 49, 231-244.

Hagdorn, H. (2011). Triassic: the crucial period of post-Palaeozoic crinoid diversification. Swiss Journal of Palaeontology, 130, 91-112.

Kitazawa, K., \& Oji, T. (2010). Particle selection by the sea lily Metacrinus rotundus Carpenter 1884 (Echinodermata, Crinoidea). Journal of Experimental Marine Biology and Ecology, 395, 80-84.

Kitazawa, K., \& Oji, T. (2014). Active feeding behavior of and current modification by the sea lily Metacrinus rotundus Carpenter 1884 (Echinodermata: Crinoidea). Journal of Experimental Marine Biology and Ecology, 453, 13-21.

Lawrence, J. (1987). A functional biology of echinoderms. Baltimore: Johns Hopkins University Press.

Macurda, D. B., Jr., \& Meyer, D. L. (1974). Feeding posture of modern stalked crinoids. Nature, 247(5440), 394-396.

Messing, C. G. (1985). Submersible observations of deep-water crinoid assemblages in the tropical western Atlantic Ocean. In B. O. Keegan \& B. S. Connor (Eds.), Proceedings of the Fifth 
international echinoderm conference, Galway, Ireland (pp. 185-193). Rotterdam: Balkema.

Messing, C. G., Rosesmyth, S. R., Mailer, S. R., \& Miller, J. F. (1988). Relocation movement in a stalked crinoid (Echinodermata). Bulletin of Marine Science, 42, 480-487.

Neto de Carvalho, C., Pereira, B., Klompmaker, A., Baucon, A., Moita, J. A., Pereira, P., et al. (2016). Running crabs, walking crinoids, grazing gastropods: behavioral diversity and evolutionary implications of the Cabeço da Ladeira Lagerstätte (Middle Jurassic, Portugal). Comunicações Geológicas, 103(Especial I), $39-54$.

Oji, T. (1986). Skeletal variation related to arm regeneration in Metacrinus and Saracrinus, Recent stalked crinoids. Lethaia, 19, 355-360.
Salamon, M. A. (2003). Middle Triassic crinoids (Crinoidea) from the Holy Cross Mountains. Unpubl. Ph.D. thesis (University of Silesia, Sosnowiec), pp. 1-112.

Senkowiczowa, H. (1982). Struktury biogeniczne w osadach retu i wapienia muszlowego Gór Świętokrzyskich. Kwartalnik Geologiczny, 26, 559-583.

Simms, M. J. (1999). Sytematics, phylogeny and evolutionary history. In H. Hess, W. I. Ausich, C. E. Brett, \& M. J. Simms (Eds.), Fossil Crinoids (pp. 31-40). Cambridge: Cambridge University Press.

Twitchett, R. J., \& Oji, T. (2005). Early Triassic recovery of echinoderms. Comptes Rendus Palevol, 4, 531-542. 